\title{
Pelatihan dan Lomba Menulis Opini bagi Pelajar, Rohaniwan dan Umat Katolik dalam Rangka Hari Komunikasi Sosial Sedunia 2021
}

\author{
Budi Sutedjo Dharma Oetomo ${ }^{1}$ \\ ${ }^{1}$ Program Studi Sistem Informasi, Fakultas Teknologi Informasi, Universitas Kristen Duta Wacana \\ Jl. Dr. Wahidin Sudirohusodo 5-25, Yogyakarta \\ ${ }^{1}$ Email: budi@staff.ukdw.ac.id
}

\begin{abstract}
Abstrak - Perayaan hari Komunikasi Sosial sedunia tahun 2021 dilangsungkan Komisi Komunikasi Sosial Konferensi Waligereja Indonesia secara online dengan tema "Datang dan Lihatlah" dalam bentuk pelatihan dan lomba menulis opini. Perayaan tersebut menjadi momentum untuk membangkitkan kesadaran umat tentang pentingnya untuk melakukan komunikasi melalui perjumpaan apa adanya, serta menggunakan media-media komunikasi secara bertanggung jawab. Persoalan utama yang dihadapi adalah meningkatkan animo umat untuk mengikutinya. Untuk mengatasi persoalan itu, diterapkan perpaduan metode pelatihan dengan lomba penulisan opini seperti tahun lalu dengan beberapa perbaikan berupa penambahan frekuensi dan durasi pelatihan. Selain itu, peserta lomba dibagi dalam tiga kategori, yaitu pelajar, rohaniwan dan umat secara umum, dan peningkatan nilai dan penambahan jumlah hadiah berupa uang pembinaan, serta penambahan kuota karya nominator yang dibukukan. Ternyata, perbaikan metode tersebut telah mendorong peningkatan jumlah peserta hingga $25 \%$ dibandingkan tahun sebelumnya. Penambahan banyak terjadi pada kategori pelajar dan rohaniwan, khususnya para biarawati Katolik. Opini yang tersaji pun sangat beragam dan mendalam. Jadi, perbaikan metode itu penting dan berdampak pada peningkatan partisipasi umat dari semua kategori, bahkan umat yang belum memiliki keterampilan menulis opini pun berani ambil bagian dalam kegiatan tersebut.
\end{abstract}

Kata kunci- hari komunikasi sosial sedunia, komunikasi sosial, lomba menulis opini, pelatihan online menulis opini.

Abstract - The celebration of the World Social Communications Day in 2021 was held by the Indonesian Bishops Conference's Social Communications Commission by online with the theme "Come and See" in the form of training and opinion writing competitions. The celebration became a momentum to raise people's awareness about the importance of communicating through real-life encounters, as well as using communication media responsibly. The main problem faced is increasing the interest of the people to follow it. To overcome this problem, a combination of training methods and opinion writing competitions was applied as last year with several improvements in the form of increasing the frequency and duration of the training. In addition, the participants of the competition were divided into three categories, namely students, clergy and people in general, and increasing the value and increasing the number of prizes in the form of coaching money, as well as increasing the quota of nominees' works that were recorded. It turned out that the improvement of the method had boosted the number of participants by up to $25 \%$ compared to the previous year. Many additions occurred in the category of students and clergy, especially Catholic nuns. Opinions presented are also very diverse and profound. So, improving the method is important and has an impact on increasing the participation of people from all categories, even people who do not yet have the skills to write opinions dare to take part in these activities.

Keywords - world social communication day, social communication, opinion writing contest, opinion writing online training.

\section{PENDAHULUAN}

Setiap tahun, pada minggu Paskah ke VII [1], umat Katolik di seluruh dunia merayakan hari Komunikasi Sosial se-dunia. Pada tahun ini, puncak perayaan tersebut dilakukan pada hari Minggu, 16 Mei 2021 yang lalu.

Umat Katolik dari 37 Keuskupan di Indonesia pun tidak ketinggalan untuk ikut merayakannya. Komisi Komunikasi Sosial Konferensi Waligereja Indonesia (KomSos KWI) menyelenggarakan sejumlah kegiatan untuk memeriahkan perayaan tersebut, antara lain dengan melakukan kegiatan pelatihan dan lomba dengan tujuan untuk mensosialisasikan pesan Paus Fransiskus yang diberi tema "Datang dan Lihatlah: berkomunikasi dengan menjumpai orang lain apa adanya". Tema tersebut terinspirasi dari Injil Yohanes 1:46 [2]. 
Perayaan hari Komunikasi Sosial se-dunia itu menjadi momentum untuk membangkitkan kesadaran umat tentang pentingnya untuk melakukan komunikasi melalui perjumpaan apa adanya, serta menggunakan media-media komunikasi secara bertanggung jawab. Oleh karena itu, Komisi KomSos KWI telah mengemas aneka kegiatan yang dilangsungkan secara online pada tahun ini, meliputi:

1. Pelatihan dan lomba penulisan opini

2. Komsoslympics 2021

3. Pelatihan dan lomba cipta lagu

4. Pelatihan dan lomba cipta konten kreatif digital

5. Pelatihan dan lomba podcast pewartaan

6. Pelatihan dan lomba video bercerita

7. Pelatihan dan lomba penulisan artikel di media massa

Semua kegiatan lomba untuk memeriahkan perayaan tersebut diawali dengan proses pelatihan, karena komisi KomSos KWI dan Keuskupan memiliki misi untuk mempersiapkan umat, agar mereka mampu berkomunikasi dengan memanfaatkan aneka media secara kreatif, inovatif dan efektif.

Masing-masing kegiatan dimulai dari bulan April 2021 dan berpuncak pada perayaan hari Komunikasi Sosial sedunia, termasuk di antaranya pelatihan dan lomba menulis opini bagi para pelajar, rohaniwan dan umat Katolik Indonesia (Gambar 1).

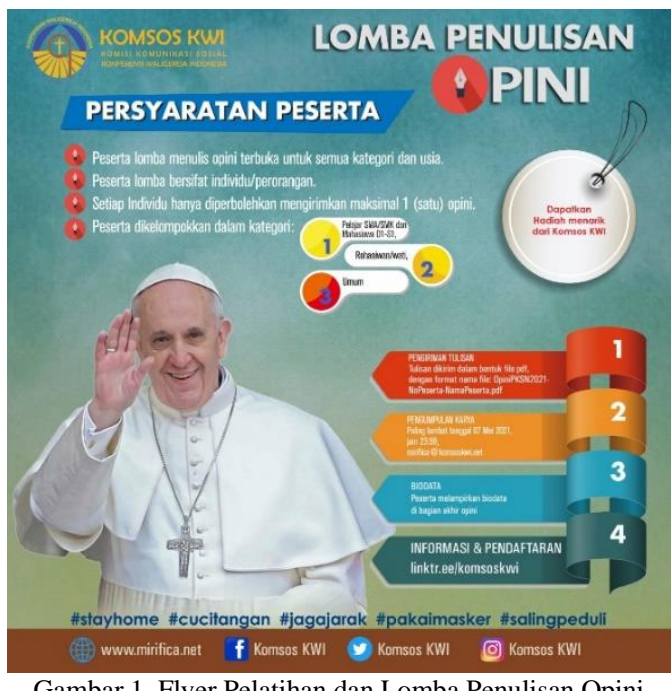

Kegiatan serupa pernah dilakukan pada perayaan hari Komunikasi Sosial se-dunia ke-54 tahun 2020 yang lalu. Dari pengalaman penyelenggaraan tahun lalu, maka pada penyelenggaraannya yang ke-2 pada tahun ini telah dilakukan perubahan-perubahan, agar kegiatan pelatihan dan lomba menulis opini tersebut dapat lebih menarik minat umat untuk terlibat dan berpartisipasi dalam mengungkapkan pendapatnya[3] terhadap pesan Paus Fransiskus dalam peringatan hari Komunikasi Sosial sedunia tersebut.

\section{PERMASALAHAN}

Persoalan yang dihadapi oleh komisi Komunikasi Sosial KWI adalah meningkatkan animo umat untuk mengikuti kegiatan-kegiatan tersebut, khususnya dalam pelatihan dan lomba opini, karena terkait dengan peran komisi untuk mensosialisasikan pesan Paus Fransiskus dan meningkatkan partisipasi umat dalam menanggapi pesan tersebut yang dituangkan dalam bentuk tulisan opini.

Keikutsertaan umat dalam mengungkapkan pendapat tersebut sangat penting, karena partisipasi umat itu menunjukkan keberlangsungan komunikasi dua arah antara Paus Fransiskus yang diwakili oleh komisi Komunikasi Sosial KWI dengan umat.

\section{METODE PELAKSANAAN}

Pelatihan dan lomba menulis opini dalam rangka perayaan hari Komunikasi Sosial se-dunia ke-55 diselenggarakan oleh Komisi KomSos KWI dengan tahapan dari persiapan hingga pasca kegiatan sebagai berikut:

\section{A. Tahap Persiapan}

Tahap persiapan dilakukan lebih awal dibandingkan dengan persiapan kegiatan yang sama pada tahun lalu. Kegiatan pada tahap persiapan ini dilakukan sebagai berikut:

1. Akhir Januari 2021 dilakukan koordinasi Badan Pengurus Komisi KomSos KWI untuk mendalami draft pesan Paus Fransiskus pada hari Komunikasi Sosial se-dunia dengan tema pokok "Datang dan Lihatlah" (Gambar 2).

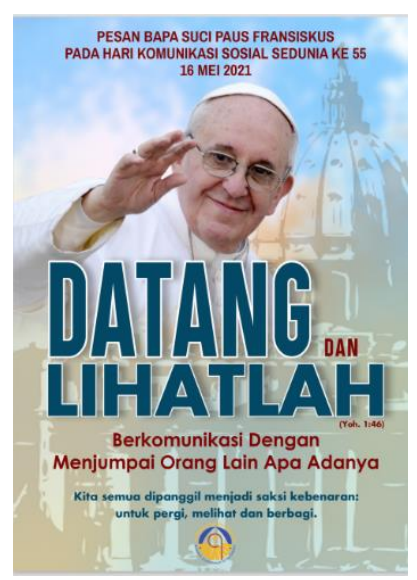

Gambar 2. Sampul pesan Bapa Suci Paus Fransiskus pada hari Komunikasi Sosial se-dunia ke-55

2. Bulan Februari 2021 dilakukan pembentukan panitia pelaksana dan penentuan koordinator dan 
narasumber untuk kegiatan pelatihan dan lomba opini dengan susunan sebagai berikut:

a. Budi Sutedjo Dharma Oetomo, S.Kom., MM, Dosen FTI-UKDW, Penggagas Indonesia Menulis, Peraih Sertifikat Penghargaan Museum Rekor-Dunia Indonesia (MURI) dan Lembaga Prestasi Indonesia Dunia (LEPRID) di bidang penulisan, Anggota Badan Pengurus Komisi KomSos KWI selaku koordinator kegiatan, narasumber pelatihan dan ketua dewan juri lomba penulisan opini.

b. Prof. Dr. Richardus Eko Indrajit, Guru Besar bidang Komputer Perbanas Institute, Rektor Pradita University Jakarta, Anggota Badan Pengurus Komisi KomSos KWI selaku anggota dewan juri lomba penulisan opini.

c. Dr. Puspita, Dosen Sekolah Kajian Stratejik dan Global Universitas Indonesia, Anggota Badan Pengurus Komisi KomSos KWI selaku anggota dewan juri lomba penulisan opini.

d. RD. Semuel Sirampun, Ketua Komisi KomSos Keuskupan Agung Makassar, Anggota Badan Pengurus Komisi KomSos KWI selaku anggota dewan juri lomba penulisan opini.

e. RD. Anthonius Steven Lalu, Sekretaris Komisi Komunikasi Sosial (KomSos) KWI, selaku anggota dewan juri lomba penulisan opini.

3. Selanjutnya, panitia menetapkan jadwal dari tahapan pelaksanaan pelatihan dan lomba penulisan opini (Gambar 3) sebagai berikut:

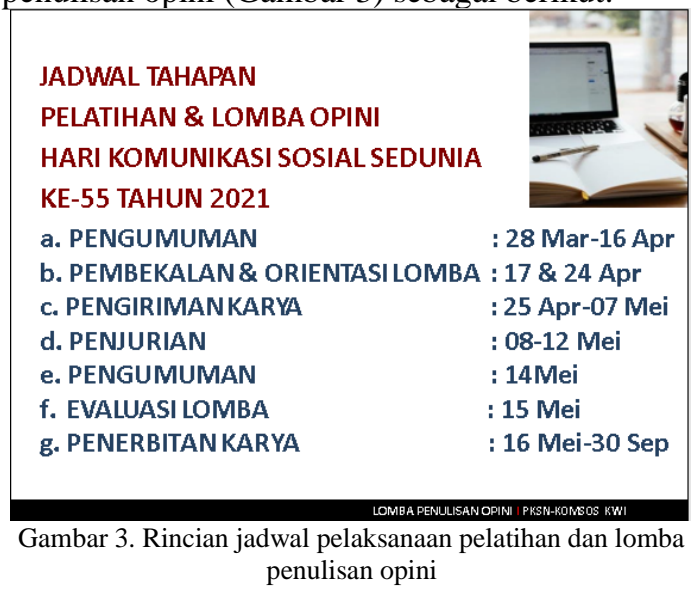

4. Pengumuman kegiatan pelatihan dan lomba penulisan opini melalui laman Web mirifica.net (Gambar 4) yang merupakan sarana komunikasi resmi Gereja Katolik Indonesia dan didukung penyebarluasannya oleh jejaring Komisi KomSos Keuskupan seluruh Indonesia, sehingga informasi tersebut dapat diterima oleh Gereja, Sekolah, Seminari, Biara-biara dan umat Katolik seluruh Indonesia. Untuk menghimpun data pendaftar disediakan $e$-form [4].

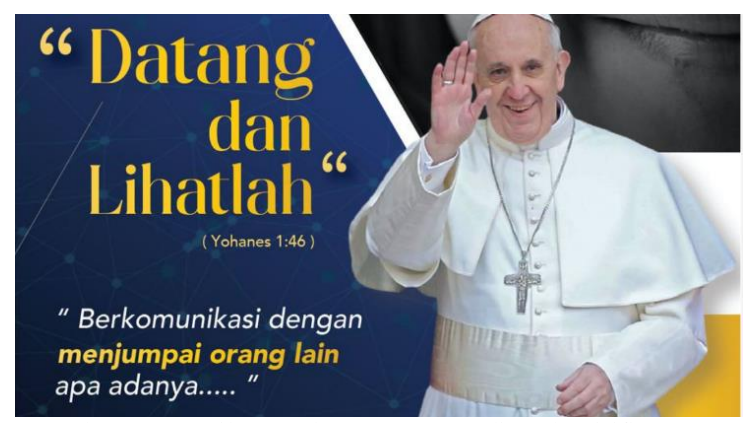

Gambar 4. Tampilan awal pengumuman di Web mirifica.net

\section{B. Tahap Pelatihan}

Pada tanggal 17 dan 24 April 2021 dilakukan pelatihan penulisan opini secara online melalui aplikasi Zoom [5]. Bertindak selaku narasumber tunggal yaitu Budi Sutedjo Dharma Oetomo, S. Kom., MM yang mengetengahkan beberapa materi (Gambar 5) yang terdiri dari

1. Teknik Penulisan Opini (pendapat subyektif)

2. Teknik Penulisan Artikel (pendapat objektif)

3. Pendalaman pesan Paus Fransiskus: "Datang dan Lihatlah"
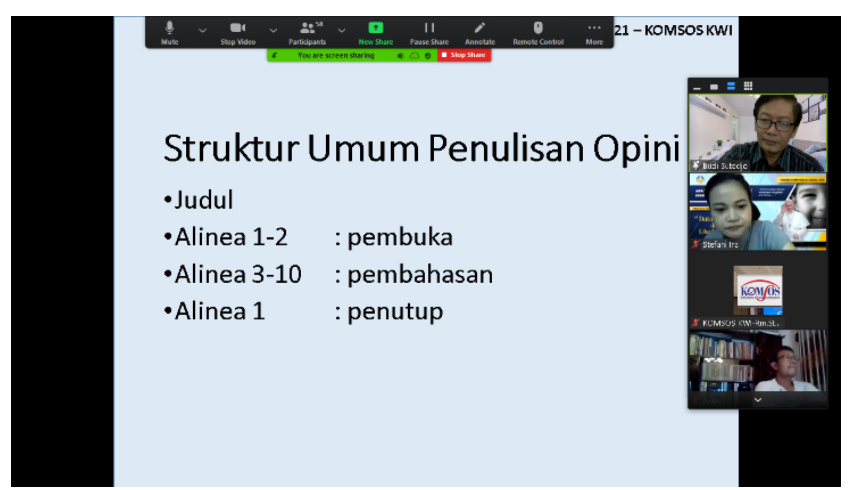

Gambar 5. Pelaksanaan pelatihan penulisan opini Hari Komunikasi Sosial se-dunia 2021

\section{Tahap Praktik Penulisan Opini}

Setelah peserta mengikuti pelatihan penulisan opini yang dilakukan sebanyak dua sesi, peserta diberi waktu untuk menuliskan pendapatnya terhadap pesan Paus Fransiskus yang bertajuk "Datang dan Lihatlah" tersebut mulai 17 April - 7 Mei 2021. Bagi peserta yang telah selesai menyusun tulisan opininya dapat mengirimkan ke alamat email panitia mulai tanggal 25 April-7 Mei 2021

Saat peserta praktik menulis opini, peserta diberi kesempatan untuk berkonsultasi dengan narasumber melalui grup WA [6] yang disediakan oleh panitia. Konsultasi peserta melalui grup WA tersebut dirancang 
dengan tujuan supaya pertanyaan dari peserta yang satu dapat menjadi pembelajaran bagi peserta yang lain.

Pada hari terakhir pengumpulan karya, tercatat sebanyak 109 orang yang mengumpulkan opininya. Jumlah itu meningkat $25 \%$ dari tahun sebelumnya, dimana jumlah peserta pada tahun sebelumnya hanya 87 orang. Dari 109 peserta tersebut terbagi dalam kategori umum 49 orang, kategori rohaniwan 34 orang dan kategori pelajar (dan mahasiswa) 26 orang.

\section{Tahap Penjurian}

Sesuai jadwal, penjurian dilakukan pada tanggal 8-12 Mei 2021. Namun, karena jumlah tulisan yang masuk sangat banyak, maka proses penjurian berlangsung hingga tanggal 15 Mei 2021.

Proses penjurian berlangsung 3 tahap, dimana pada tahap pertama, tulisan peserta diseleksi dengan kriteria umum [7], yaitu:

1. Keterkaitan opini dengan pesan Paus Fransiskus.

2. Sistematika atau struktur alur opini.

3. Kreativitas dalam menemukan sudut pandang atau keunikan gagasan dalam menanggapi pesan Paus.

4. Ketajaman tanggapan penulis.

5. Daya ajak atau daya gerak bagi pembaca untuk berbuat sesuai pesan Paus.

6. Gaya bahasa yang komunikatif dan kemudahaan untuk dipahaminya pendapat penulis.

Dari proses penjurian tahap pertama itu ditetapkan 43 nominator yang terdiri dari 15 orang peserta umum, 16 orang peserta rohaniwan dan 12 orang peserta pelajar. Jumlah nominator banyak, karena memang tulisan opini mereka tergolong menarik, kreatif dalam menemukan sudut pandang, serta komunikatif.

Selanjutnya, pada tahap kedua, dewan juri kembali membaca tulisan peserta nominator dan berusaha untuk menetapkan 5 karya yang dipilih menjadi kandidat juara untuk masing-masing kategori berdasarkan 6 kriteria umum dengan fokus pada kriteria kreativitas, ketajaman dan daya ajak. Tahap terakhir dari penjurian adalah menentukan urutan juara 1-3 dan juara harapan 1-2 dari masing-masing kategori.

Hasil penjurian berupa daftar juara 1-3, juara harapan 12 dan nominator dikirimkan oleh dewan juri kepada sekretariat komisi KomSos KWI melalui email untuk dirancang bentuk pengumumannya.

\section{E. Tahap Evaluasi Karya}

Kegiatan pelatihan dan lomba penulisan opini ini tidak berhenti pada saat ditetapkannya juara. Namun, pada tanggal 15 Mei 2021, kembali diselenggarakan pertemuan, dimana ketua dewan juri memberikan ulasan dan evaluasi terhadap tulisan peserta yang telah dibaca dan dinilai oleh dewan juri (Gambar 6).
Tujuan dari pertemuan evaluasi karya [8] tersebut adalah peserta mengetahui kekurangan atau alasan peserta tidak menjadi nominator atau bahkan menjadi juara, agar mereka dapat menghasilkan tulisan opini yang lebih baik lagi di masa mendatang.

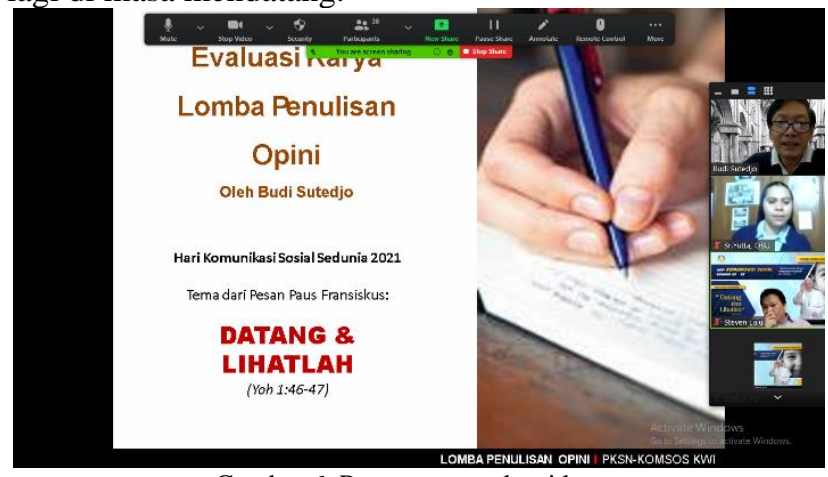

Gambar 6. Pertemuan evaluasi karya

\section{F. Tahap Pengumuman Juara}

Pengumuman dilangsungkan pada puncak perayaan Hari Komunikasi Sosial se-dunia pada hari Minggu, $16 \mathrm{Mei}$ 2021 (Gambar 7). Selanjutnya, sekretariat Komisi KomSos KWI mengirimkan pemberitahuan resmi dan informasi proses transfer hadiah berupa uang pembinaan. Kepada narasumber, dewan juri dan seluruh peserta diberikan sertifikat sebagai kenang-kenangan dari kegiatan pelatihan dan lomba penulisan opini hari Komunikasi Sosial se-dunia 2021.

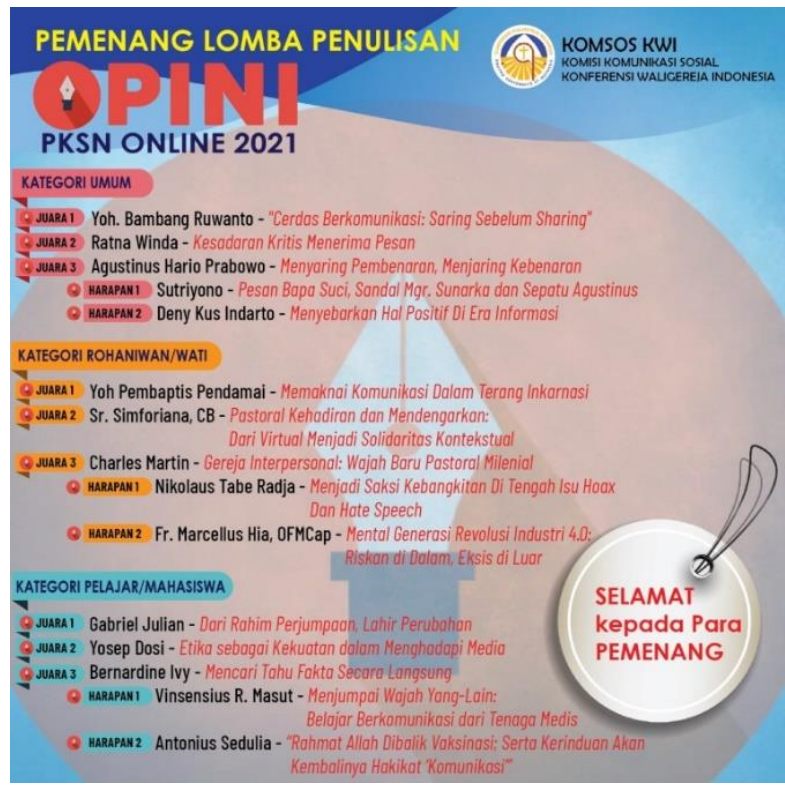

Gambar 7. Daftar juara lomba penulisan opini dalam rangka Hari Komunikasi Sosial se-dunia ke-55

\section{G. Tahap Penerbitan Tulisan}


Selanjutnya, tulisan opini dari peserta yang menjadi juara dan nominator, beserta tulisan dari narasumber, dewan juri dan anggota Badan Pengurus Komisi KomSos KWI diproses untuk diterbitkan dalam bentuk $e$-book bunga rampai. E-book tersebut direncanakan diterbitkan pada penutupan bulan Kitab Suci tanggal 30 September 2021.

\section{HASIL DAN PEMBAHASAN}

Animo peserta merupakan persoalan atau kekhawatiran utama panitia penyelenggara pelatihan dan lomba penulisan opini. Panitia mengatasi persoalan animo peserta tidak dengan meningkatkan frekuensi promosi, melainkan dilakukannya perbaikan terhadap metode pelaksanaannya, yaitu:

1. Perbaikan metode pelatihan [9] dari segi frekuensi. Dibandingkan dengan penyelenggaraan tahun sebelumnya, frekuensi pelatihan ditingkatkan menjadi dua kali lipat dan durasi waktu ditambah dari semula 2 jam menjadi 3 jam. Tujuan perbaikan metode pelatihan ini untuk meraih penulis pemula yang masih membutuhkan pembekalan tentang teknik penulisan opini dan motivasi untuk menumbuhkan kepercayaan diri [10].

2. Pengelompokan peserta lomba dalam tiga kategori, yaitu pelajar, rohaniwan dan umat secara umum. Peserta yang tergolong pelajar yaitu siswa SMA atau SMK dan mahasiswa. Peserta yang tergolong rohaniwan yaitu pastor, bruder (biarawan) dan suster (biarawati). Pemisahan peserta lomba dalam tiga kategori ini untuk menempatkan peserta dalam ruang kompetisi yang seimbang.

3. Hadiah berupa uang pembinaan ditingkatkan jumlah dan nilainya, serta penambahan kuota tulisan nominator yang akan dibukukan. Insentifinsentif tersebut ditingkatkan untuk menumbuhkan motivasi peserta dalam mengikuti kegiatan pelatihan [11] dan lomba penulisan opini.

Ternyata, perbaikan metode tersebut telah mendorong peningkatan jumlah peserta hingga $25 \%$ dibandingkan tahun sebelumnya. Penambahan banyak terjadi pada kategori pelajar dan rohaniwan khususnya biarawati. Tulisan-tulisan opini yang dihasilkan pun sangat beragam dan mendalam. Jumlah tulisan opini yang menjadi nominator meningkat drastis dari 13 buah pada tahun 2020 menjadi 43 pada tahun 2021

Seiring dengan peningkatan animo,ditemukan adanya kategori yang ambigu bagi kriteria pelajar dan mahasiswa. Dimana, pada saat penentuan kategori itu, panitia membayangkan peserta adalah siswa SMA/ SMK dan mahasiswa Diploma dan mahasiswa S1, sedangkan dalam kenyataannya ada mahasiswa S2 dan S3 yang ikut mendaftarkan diri, sehingga ruang kompetisi untuk kategori pelajar menjadi tidak seimbang. Selain itu, terjadi kebingungan untuk peserta dengan status sebagai frater (calon pastor) yang umumnya dipandang umat tergolong sebagai rohaniwan, tetapi berdasarkan hokum Gereja, mereka belum tergolong sebagai rohaniwan, karena mereka belum ditahbiskan (dilantik) menjadi pastor (imam).

Ditilik dari materi pelatihan yang diberikan narasumber, maka dapat dipastikan bahwa peserta dapat membedakan tulisan opini (pendapat subjektif) dan tulisan artikel (pendapat objektif). Tulisan opini berisi pendapat spontan penulis terhadap kejadian, fenomena atau unsur-unsur fakta yang dirumuskan sebagai $5 \mathrm{~W}+1 \mathrm{H}$, sedangkan artikel berisi pendapat objektif penulis terhadap kejadian, fenomena atau unsur-unsur fakta, dimana objektivitas pendapat penulis ditunjukkan dengan adanya rujukan pada pendapat tokoh, peneliti, ilmuwan, akademisi atau penulis lainnya. Setelah memahami perbedaan tulisan opini subjektif dan objektif itu, selanjutnya, peserta diberi kesempatan untuk menentukan jenis tulisan opini yang akan ditulisnya.

Dari total 109 peserta yang mendaftar lahir 109 tulisan opini. Hal itu menunjukkan bahwa:

1. Peserta yang mendaftar benar-benar mau berlatih menjadi penulis opini. Sebagian besar dari peserta merupakan penulis pemula.

2. Dalam diri mereka pun tumbuh rasa percaya diri atas karya yang dihasilkan, sehingga mereka berani mengikutsertakan hasil karyanya dalam lomba.

3. Partisipasi peserta tidak semata-mata digerakkan oleh insentif yang nilai lebih besar dan lebih banyak jumlahnya, melainkan diidentifikasi adanya pertumbuhan inisiatif dari dalam diri peserta yang tampak dari keikutsertaannya secara penuh saat pelatihan dan kesesuaian karya dengan pola yang diajarkan dalam pelatihan. Inisiatif itu akan menjadi modal dasar untuk bertumbuh menjadi penulis profesional di masa yang akan datang.

Kesempatan konsultasi melalui WA grup menjadi sarana bagi peserta untuk memastikan opini yang ditulis sesuai dengan kriteria lomba. Selain itu, konsultasi dapat meningkatkan kualitas tulisan yang disusun peserta, karena mereka mendapatkan sudut pandang - sudut pandang atau inspirasi-inspirasi baru dari narasumber. Sementara itu, evaluasi karya menjadi sarana bagi peserta untuk mengetahui bagian-bagian dari tulisan yang masih perlu diperbaiki, sehingga kelak mereka dapat menghasikan tulisan-tulisan yang lebih fokus, kreatif sudut pandang dan bahasannya, serta memiliki daya ajak bagi pembaca.

Usaha panitia untuk membukukan hasil karya peserta perlu dibudayakan, agar umat pada khususnya dan masyarakat pada umumnya memiliki pustaka-pustaka bacaaan baru yang berisi pandangan-pandangan dan bahasan-bahasan terhadap pesan-pesan terkini dari pimpinan Gereja sekaligus tokoh dunia. 


\section{KESIMPULAN}

Usaha perbaikan terhadap metode pelaksanaan kegiatan pelatihan dan lomba yang dilakukan panitia sangat berdampak pada peningkatan partisipasi umat dari semua kategori, bahkan umat yang belum terampil menulis opini pun berani ambil bagian dalam kegiatan tersebut, karena mereka diberi pelatihan dan kesempatan untuk berkonsultasi selama proses penulisan. Peningkatan animo peserta mencapai $25 \%$ membuktikan bahwa perbaikan metode pelaksanaan itu menjadi solusi yang tepat.

Umat membutuhkan model lomba yang dipadukan dengan kegiatan pelatihan. Perpaduan lomba dengan pelatihan itu terbukti telah mampu membangun inisiatif, motivasi dan keberanian peserta yang tergolong belum terampil menulis opini untuk ikut ambil bagian dalam lomba. Selain itu, pelatihan yang dilengkapi dengan kesempatan konsultasi telah menunjang peserta untuk menghasilkan tulisan yang sesuai dengan kriteria lomba dan kualitas untuk dipilih menjadi nominator bahkan juara lomba.

Publikasi karya yang dikemas dalam bentuk e-book telah memotivasi peserta untuk menghasilkan tulisan yang berkualitas, agar mereka dapat ikut berpartisipasi dalam mencerdaskan umat dan masyarakat melalui penyediaan pustaka elektronik.

Untuk penyelenggaraan kegiatan sejenis pada tahun 2022 yang akan datang, maka panitia perlu membuat kategori khusus bagi mahasiswa S2 dan S3, serta memperjelas kategori dari peserta dengan status sebagai frater (seminaris).

\section{UCAPAN TERIMA KASIH}

Penulis mengucapkan terima kasih yang sebesarbesarnya kepada Komisi Komunikasi Sosial Konferensi
Waligereja Indonesia yang telah menyelenggarakan kegiatan pengabdian kepada masyarakat tersebut dan melibatkan penulis dalam beberapa peran, baik sebagai narasumber, koordinator lomba dan tim juri.

\section{DAFTAR PUSTAKA}

[1] Komisi Komunikasi Sosial Konferensi Waligereja Indonesia. (2021). Tata Perayaan Ekaristi Hari Komunikasi Sosial Sedunia ke 55. Jakarta: Komisi Komunikasi Sosial Konferensi Waligereja Indonesia.

[2] Fransiskus. (2021). Datang dan Lihatlah: berkomunikasi dengan menjumpai orang lain apa adanya. Jakarta: Konferensi Waligereja Indonesia.

[3] Bailey, S. (2011). Academic Writing. New York: Routledge.

[4] Charolina, Y., \& Honny. (2021). Pemamfaatan Aplikasi Googleform Dalam Pembelajaran Bagi Guru Pada Masa Pandemi. Paradigma, 17-24.

[5] Monica, J., \& Fitriawati, D. (2020). Efektivitas Penggunaan Aplikasi Zoom Sebagai Media Pembelajaran Online Pada Mahasiswa Saat Pandemi Covid-19. Jurnal Communio, 1630-1640.

[6] Khasanah, Nasan, E., \& Jus'aini. (2021). Efektifitas Media Whatsapp Group Dalam Pembelajaran Daring. Jurnal Teknologi Pendidikan, 47-65.

[7] Oetomo, B. S. (2020). Pelatihan Menulis Opini secara Online bagi Umat Katolik Indonesia dalam rangka Hari Komunikasi Sosial seDunia ke-54. Sendimas 2020 (pp. 213-216). Yogyakarta: Universitas Atma Jaya Yogyakarta.

[8] Haryanto. (2020). Evaluasi Pembelajaran. Yogyakarta: UNY Press.

[9] Sarwade, W. K., \& Sharma, D. (2018). Study on Training Effectiveness of training Methods and Techniques of Employees Working in Corporate Sector. Iaetsd Journal For Advanced Research In Applied Sciences, 209-223.

[10] Malureanu, A., Panisoara, G., \& Lazar, I. (2021). The Relationship between Self-Confidence, Self-Efficacy, Grit, Usefulness, and Ease of Use of eLearning Platforms in Corporate Training during the COVID-19 Pandemic. Sustainability, 1-20.

[11] Docan, T. N. (2006). Positive and Negative Incentives in the Classroom: An Analysis of Grading Systems and Student Motivation. Journal of Scholarship of Teaching and Learning, 21- 